\title{
Pattern of electrical activity of the ovine uterus and cervix from mating to parturition
}

\author{
R. Garcia-Villar, P. L. Toutain and Y. Ruckebusch \\ Institut National de la Recherche Agronomique, Station de Pharmacologie-Toxicologie, 180 chemin \\ de Tournefeuille, 31300 Toulouse, France
}

\begin{abstract}
Summary. The electrical activity of the uterus, greater curvature and lesser curvature, and of the cervix were recorded throughout several oestrous cycles, matings and the entire course of pregnancy in a set of ewes. In cyclic ewes, all electrode sites were active during the periovulatory period, but during the luteal phase only the cervix and lesser curvature continued to present regular activity, i.e. episodes of 6-8 min duration. Matings failed to disrupt the oestrous activity pattern in 5 out of 6 ewes. During the subsequent pregnancy in 4 ewes, activity, when present, consisted of the cyclic occurrence of regular activity episodes in the gravid horn(s) (greater curvature) and in the cervix (and lesser curvature in 1 ewe). Three phases were recognized on the basis of the activity of the greater curvature of the gravid horn(s). The first phase corresponded to quiescence of the horn from Day 5 (Day $0=$ mating) to about Day 41 . The second phase was marked by the sudden onset of regular activity of the uterus; frequency rapidly increased and maximal values were reached around Day 49, after which frequency progressively decreased until around Day 66. The third phase was characterized by a steady state in genital tract activity until the peripartum period. The cervix and lesser curvature activity followed an almost similar development of regular activity episodes with only slight time differences.
\end{abstract}

\section{Introduction}

Data concerning the motility of the genital tract of the ewe during pregnancy have been generally limited to the peripartum period (Hindson, Schofield \& Turner, 1968; Hindson \& Ward, 1973; Naaktgeboren et al., 1975; Prud'homme \& Bosc, 1977; Krishnamurti, Kitts, Kitts \& Tompkins, 1982). Motor activity episodes in the uterus of ewes have been described during the last third (Nathanielsz, Bailey, Poore, Thorburn \& Harding, 1980) and the second half (Harding et al., 1982) of pregnancy. The development of the activity profile of the genital tract throughout the last month of pregnancy in the ewe has been reported (Toutain, Garcia-Villar, Hanzen \& Ruckebusch, 1983). The motor pattern is defined as the cyclic occurrence of so-called regular activity episodes on the cervix and on the gravid horn(s), and the absence of significant motility in the non-gravid horn. Few studies provide data earlier than the 70th day of pregnancy. Amongst them, the work by Van der Weyden, Taverne, Dieleman \& Fontijne (1981), using chronically implanted electrodes, reports that the onset of uterine motor activity occurs as early as the 5th week of pregnancy. This activity was shown to be present until the peripartum period. Nevertheless, only one ewe was used in that study during the entire course of pregnancy and quantitative data were limited.

Motility events during early pregnancy deserve attention in regard to the intrauterine migration of the embryo(s) and its attachment. Sheep embryo(s) enter the horns about $72 \mathrm{~h}$ after fertilization. Reimers et al. (1973) have shown that, in more than 1000 pregnant ewes with a single corpus luteum, the embryo remained in the ipsilateral horn in more than $93 \%$ of the animals. Conversely, 
they observed that, in a few ewes that had two corpora lutea in the same ovary and in which twins were being carried, one embryo had always migrated into the contralateral horn. Absence of uterine motor activity during the first 5-7 weeks of pregnancy is a possible prerequisite to allow the maintenance of the tenuous attachment of the ovine embryo, from around Day 15 until Days 45-55, when more intimate associations with the maternal endometrium appear. Currently, there is lack of information on the onset and further development of motor activity of the ovine genital tract, at least until mid-pregnancy. The aim of the present work was to describe the motility pattern of the uterine horns (greater and lesser curvatures) and of the cervix throughout the entire course of pregnancy in a set of ewes. Special attention was given to the first 4 months of pregnancy. In addition, observations were made during the oestrous cycle, and at the time of the mating which precedes pregnancy.

\section{Materials and Methods}

Six ewes of the Lacaune breed were used. None had been previously used in any experiment. The ewes were housed, were fed hay and oats ad libitum, and had free access to water. After the onset of the breeding season (August) they were fitted, under thiopentone anaesthesia and aseptic surgical conditions, with pairs of $\mathrm{Ni}-\mathrm{Cr}$ electrodes positioned in the ventral cervix and on the middle of the greater curvature of each uterine horn. In addition to this, 3 out of the 6 ewes had electrode groups at the level of the lesser curvature of both horns. Recordings made according to the technique described by Garcia-Villar, Toutain \& Ruckebusch (1982b) and compatible with the length of pregnancy, were started 1 week after surgery. The electrical activity of the genital tract was monitored continuously ( $24 \mathrm{~h}$ per day) using an integrator circuit (Latour, 1973) connected to the output of an EMG amplifier (Reega, Alvar Paris, France). Direct records of electrical activity were performed randomly for $2-6 \mathrm{~h}$ per day. Oestrus was checked according to the EMG patterns as described previously (Ruckebusch \& Buéno, 1976; Garcia-Villar, Toutain, Moré \& Ruckebusch, 1982a). Natural mating (2 rams were used) was always performed during a 'direct' recording session within the 1 st day of the periovulatory period (total duration 4 days) corresponding to the onset of uterine activity after luteal-phase quiescence. Mating took place during the 3 rd or 4 th oestrous period after surgery, and was performed 2-4 times during the day of oestrus. Integrated records were scored for periods of $24 \mathrm{~h}$. Motility events were described using the terminology (regular and irregular activity) qualified in a previous paper (Toutain et al., 1983). Charts for the pregnancy period started on Day 5 (Day $0=$ day of mating) and were taken until 2 days before parturition. Because of slight technical problems inherent to continuous $(24 \mathrm{~h} /$ day $)$ recordings, total recording time actually analysed was $3-6 \%$ less than the actual pregnancy duration for each of the ewes followed until parturition.

All the ewes became pregnant after the first series of matings. Of the 6 ewes, 4 spontaneously delivered healthy lambs at 146.50 \pm 1.73 days of pregnancy: 2 sets of twins (Ewes 2 and 4 ) and 2 singletons (Ewes 1 and 3). Only Ewe 3 bore electrodes at the lesser curvature of the uterine horns. Two other ewes that were fitted with electrodes on the lesser curvature aborted on Days 66 and 89 . Because of the technical problems encountered data for these 2 ewes were considered only for the effects of mating, and the qualitative description of the activity of the lesser curvature of the uterine horns during the oestrous cycle and the first month of pregnancy. For quantitative studies values in the text are expressed as means \pm s.d. for 4 ewes, unless otherwise indicated. The duration of activity episodes was measured using the samples of direct records taken almost daily throughout the entire pregnancy in the 4 ewes. The development of activity pattern was described (i) by visual inspection of individual curves of daily frequency against stage of pregnancy and (ii) by calculating the limits of the second of the three phases considered after analysis of the curves.

The day corresponding to the end of phase 2 was calculated in two steps; the mean frequency of regular activity was calculated for the last 60 days of pregnancy (steady state). In addition, the 
equation describing the linear decrease of frequency from peak values to the lowest values was calculated. From this equation, we calculated the day at which the frequency was equal to the mean of the last 60 days and therefore considered it to be the last day of the second phase on the uterus and on the cervix.

The day of onset of phase 2 was calculated for the cervix only. The average frequency was calculated for the first 30 days. Thereafter the equation describing the linear increase in frequency from the lowest to peak values was calculated. From this equation we calculated the first day at which the frequency was equal to the mean of the first 30 days, and therefore considered it to be the first day of phase 2 on the cervix. For the uterus, the onset of phase 2 corresponded to the appearance of regular activity.

\section{Results}

\section{Activity before mating}

The electrical pattern of the genital tract during the oestrous cycle (luteal phase and periovulatory period) has already been described (Garcia-Villar et al., 1982a) except for that for the lesser curvature of the uterine horns. The latter displayed an activity pattern that resembled the cervical pattern (Text-fig. 1). In the 3 ewes considered for this observation, episodes of regular
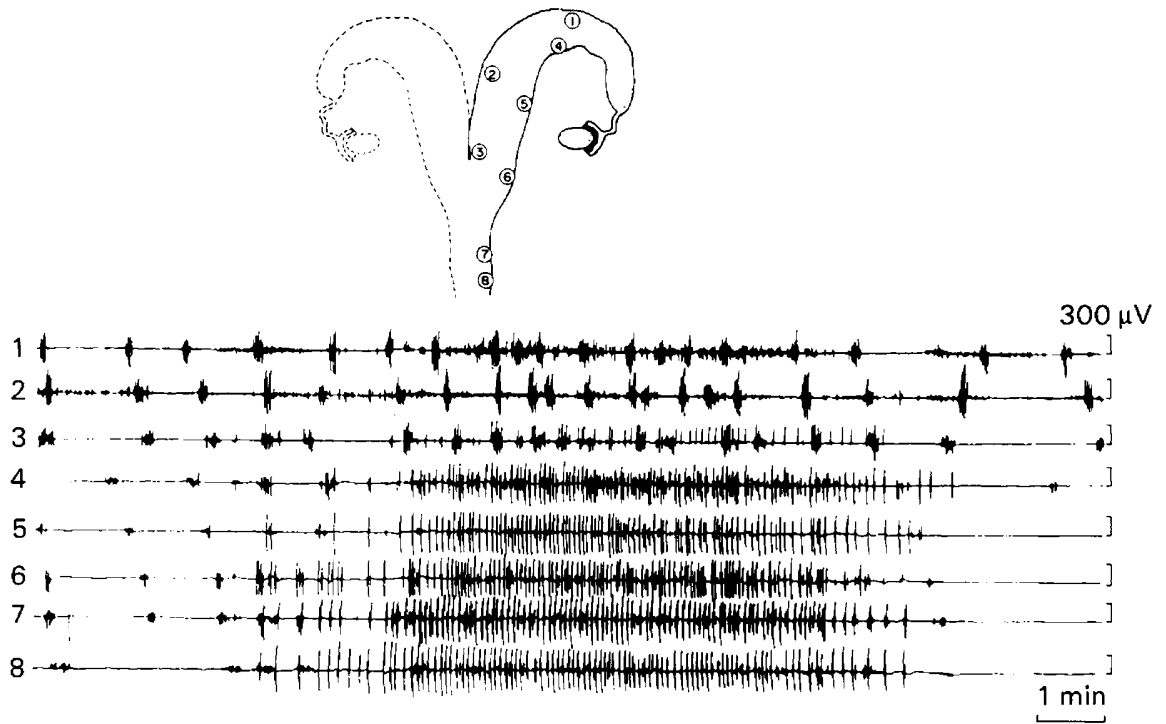

Text-fig. 1. Direct electromyogram of the greater curvature (electrodes 1,2 and 3) and lesser curvature (electrodes 4,5 and 6) of the uterine horn and of the cervix (electrodes 7 and 8 ) at the onset of the periovulatory period in the ewe. The lesser curvature presented a pattern similar to that of the cervix, i.e. regular activity episodes occurring almost simultaneously.

activity, lasting 6-8 min and formed by short spike bursts $(100-300 \mu \mathrm{V})$ in series, occurred 6-15 times/ $24 \mathrm{~h}$ during the luteal phase (13 days) and 18-43 times/24 h during the periovulatory period (4 days). The motor patterns of the lesser curvature of both horns and of the cervix were mostly synchronized, but 1-5 isolated activity episodes per day appeared on the cervix or on the lesser curvatures. 


\section{Activity at the time of mating}

Neither the entry of the ram into the recording room nor coitus itself affected significantly the records in 5 of 6 ewes. However, in one ewe a slight, but clear, inhibitory effect was observed at the time of each ejaculation and this transient inhibition was followed by omission of one episode of regular activity in the cervix (Text-fig. 2). After the end of the periovulatory period, marked by the return to quiescence of the uterus (greater curvature), the persistence of activity episodes was noted on the lesser curvature of each uterine horn and on the cervix as described above for the cyclic luteal phase. All 6 ewes became pregnant at the first series of matings.

(a)

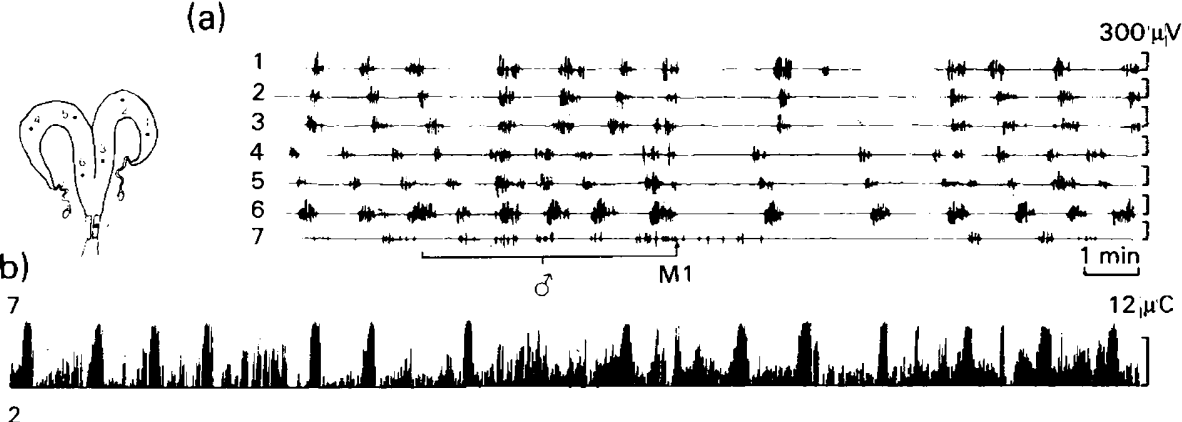

2

(b)

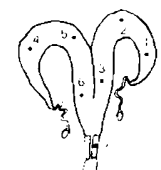

7

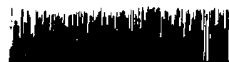

M1

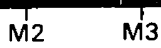

M4

$1 \mathrm{~h}$

Text-fig. 2. Direct (a) and integrated (b) electromyograms obtained for the uterus (electrodes 16) and cervix (electrode 7) at the time of mating in one ewe in which a short inhibition of activity was observed just after each ejaculation. Besides this transient inhibition, each mating seems to delay the appearance of the next episode of regular activity. $\sigma^{*}$, Presence of sire and mounting; $\mathbf{M}=$ mating.

\section{Activity pattern during pregnancy}

Qualitative aspect. The activity of the genital tract (uterus and cervix) of pregnant ewes consisted, when present, of regular activity, i.e. the periodic occurrence of episodes of sustained spiking activity, which have been shown to be related to well defined mechanical events (Toutain $e t$ al., 1983). These episodes occurred at all the electrode sites recorded, except at the level of the great curvature of the non-gravid horn. For the lesser curvature ( 3 ewes were considered for the 1 st month of gestation), regular activity episodes were identical to those described above for the oestrous cycle. In only one of these ewes, followed throughout the entire pregnancy, the activities of the lesser curvatures and the cervix were almost always synchronized. Therefore, the terms uterus or uterine horn refer to the greater curvature of the uterus unless otherwise indicated. The lesser curvature is not considered for the quantitative study.

Activity episodes occurred mainly simultaneously at the different electrode sites. Nevertheless, variable isolated episodes occurred daily on the cervix or the gravid uterus, leading to significant differences in the observed frequencies of occurrence for these sites.

Quantitative aspects. The duration of regular activity episodes, as measured during samples of direct records taken throughout pregnancy (see tables for individual values), averaged $8 \cdot 33 \pm 0.63$ min for the uterus (pregnant) and $6.86 \pm 0.82 \mathrm{~min}$ for cervix $(P<0.01$, paired $t$ test). Conversely, no differences were noticed according to the stage of pregnancy $(P>0.05$, Duncan's multiple range test) in any of the 4 ewes being studied. 
The development of uterus and cervix activities, expressed in frequency of regular activity episodes per day, is shown in Text-fig. 3. For both locations, 3 phases were distinguished. The calculations of the limits of the second phase are detailed in 'Materials and Methods'.

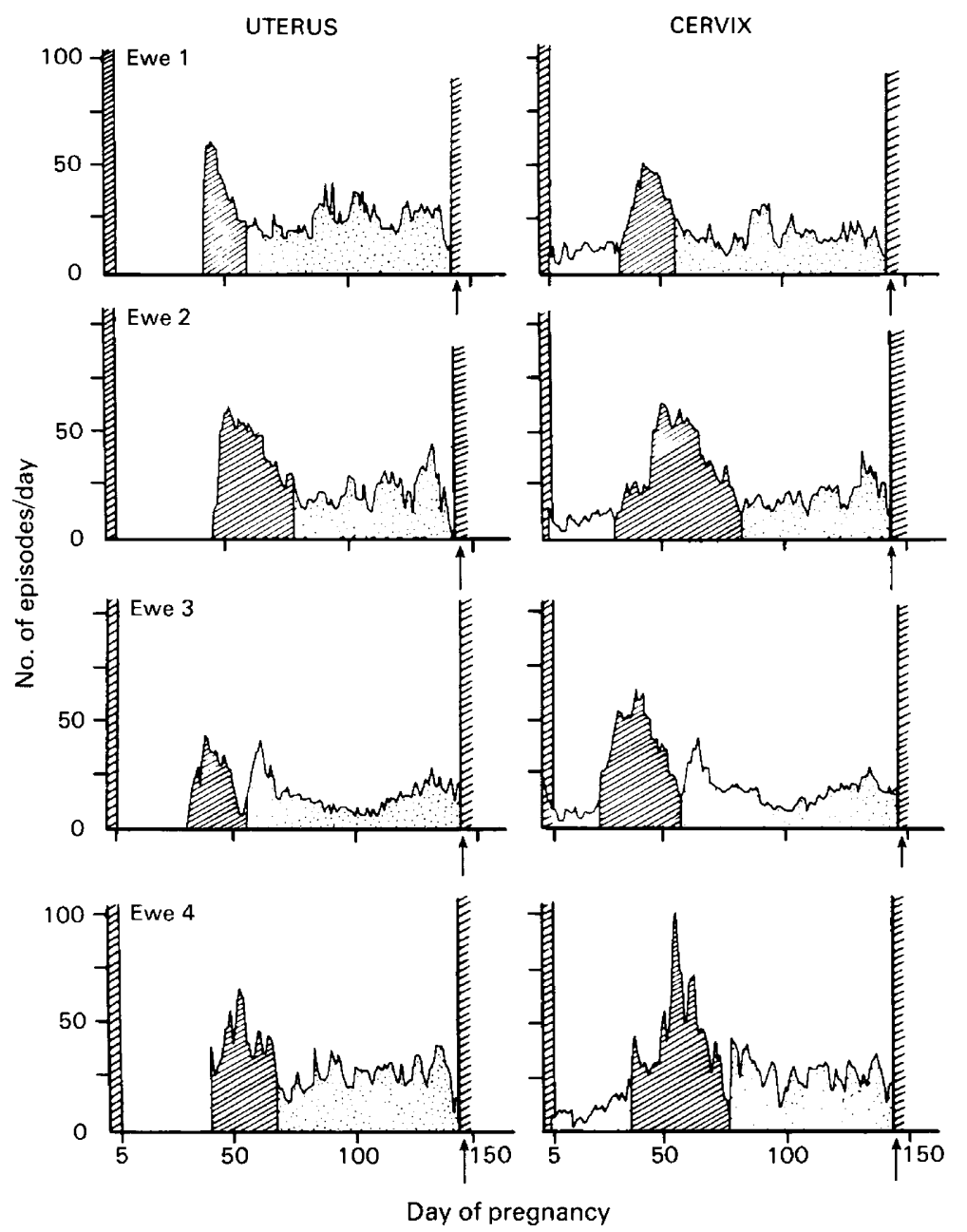

Text-fig. 3. Development of activity patterns on the pregnant uterus and the cervix during the entire course of pregnancy in each of the 4 ewes with singleton (Ewes 1 and 3) or twin (Ewes 2 and 4) pregnancies. The charts were integrated from Day 5 after mating until 2 days before parturition (arrows). White areas, phase 1; hatched areas, phase 2; stippled areas, phase 3.

Individual values and characteristics of each phase for the pregnant uterus are given in Table 1. During the first phase, from Day 5 to Day $41 \cdot 3 \pm 4 \cdot 4$, the uterine horns were totally quiescent. During the second phase, uterine activity began and increased very rapidly in the pregnant horn(s) to reach a maximum value $(59.3 \pm 9.7$ episodes/day) at $49.8 \pm 5.9$ days after mating. The nonpregnant horn, when present, remained quiescent. Thereafter the activity of the gravid uterus decreased slowly until the start of the third phase at $65.8 \pm 8 \cdot 7$ days after mating. This third phase displayed a steady frequency ( $22.6 \pm 4.5$ episodes/day) until 2 days before parturition. When the entire pregnancy period under study was considered, the uterus (pregnant) was active about $11 \%$ of the total time. Values calculated for the 2 ewes with singletons and the 2 ewes with twins presented no significant differences. 
Table 1. Timings and characteristics of electrical activity in the pregnant horn (greater curvature) of each of 4 ewes from Day 5 (Day 0 = mating) until 2 days before parturition

\begin{tabular}{|c|c|c|c|c|c|}
\hline & Ewe 1* & Ewe $2 \dagger$ & Ewe $3^{*}$ & Ewe $4 \dagger$ & Mean \pm s.d. \\
\hline \multicolumn{6}{|l|}{ Day of pregnancy } \\
\hline Onset of activity & 42 & 45 & 35 & 43 & $41 \cdot 3 \pm 4 \cdot 4$ \\
\hline Maximal activity & 47 & 53 & 43 & 56 & $49.8 \pm 5.9$ \\
\hline End of 2nd phase & 58 & 77 & 60 & 68 & $65.8 \pm 8.7$ \\
\hline \multicolumn{6}{|l|}{ Duration (days) } \\
\hline 1st phase & 37 & 40 & 30 & 38 & $36 \cdot 3 \pm 4 \cdot 4$ \\
\hline 2nd phase & 17 & 33 & 26 & 26 & $25 \cdot 5 \pm 6 \cdot 6$ \\
\hline 3rd phase & 85 & 67 & 87 & 76 & $78 \cdot 8 \pm 9 \cdot 2$ \\
\hline \multicolumn{6}{|l|}{ No. of activity episodes/day } \\
\hline lst phase & 0 & 0 & 0 & 0 & 0 \\
\hline 2nd phase $\ddagger$ & 63 & 62 & 45 & 67 & $59 \cdot 3 \pm 9.7$ \\
\hline 3rd phase§ & $\begin{array}{c}24 \cdot 9 \pm 6 \cdot 3 \\
(n=85)\end{array}$ & $\begin{array}{c}22 \cdot 6 \pm 7 \cdot 0 \\
(n=67)\end{array}$ & $\begin{array}{l}16 \cdot 4 \pm 7 \cdot 3 \\
(n=87)\end{array}$ & $\begin{array}{r}26 \cdot 6 \pm 7 \cdot 0 \\
(n=76)\end{array}$ & $22 \cdot 6 \pm 4 \cdot 5$ \\
\hline \multicolumn{6}{|l|}{ Total activity } \\
\hline Total no. of episodes & 2784 & 2851 & 2013 & 3074 & $2680.5 \pm 461.9$ \\
\hline Mean duration $(\min ) \uparrow$ & $\begin{array}{c}7 \cdot 9 \pm 1 \cdot 2 \\
(n=241)\end{array}$ & $\begin{array}{c}7 \cdot 7 \pm 1 \cdot 2 \\
(n=229)\end{array}$ & $\begin{array}{c}9 \cdot 0 \pm 1 \cdot 3 \\
(n=207)\end{array}$ & $\begin{array}{c}8 \cdot 8 \pm 2 \cdot 0 \\
(n=257)\end{array}$ & $8.4 \pm 0.6$ \\
\hline Total duration $(\mathrm{h})$ & 366.6 & 365.9 & $302 \cdot 0$ & $450 \cdot 9$ & $371 \cdot 4 \pm 61 \cdot 1$ \\
\hline Total time of pregnancy $(h) \|$ & 3336 & 3360 & 3432 & 3360 & $3372 \cdot 0 \pm 41 \cdot 6$ \\
\hline$\%$ activity of total time & $11.0 \%$ & $10.9 \%$ & $8.8 \%$ & $13 \cdot 4 \%$ & $11 \cdot \overline{0} \%$ \\
\hline
\end{tabular}

* Singleton pregnancy.

$\dagger$ Twin pregnancy.

† Peak value.

$\S$ Mean \pm s.d. for the no. of days indicated $(n)$.

I Mean \pm s.d. duration of episodes $(n)$ of regular activity measured during samples of direct records taken randomly throughout pregnancy.

\| Calculated from Day 5 until 2 days before parturition in each ewe; these values are $<6 \%$ higher than the actual time of analysis.

Individual values and characteristics of each phase for the cervix are given in Table 2. During the first phase, corresponding to uterine quiescence, the cervix presented regular activity episodes recurring with an almost stable frequency averaging $9.7 \pm 1.3$ episodes/day. This steady pattern was interrupted $7.8 \pm 2.8$ days before the onset of uterine activity of phase two. Indeed, at this time, a significant and progressive increase of frequency of regular activity episodes was observed. Peak values (range 51-100) were observed at $48.0 \pm 7.8$ days after mating. After peak values were reached, the frequency decreased progressively until a steady phase, which started $69.8 \pm 13.2$ days after mating. During this steady phase, the frequency of activity episodes averaged $20 \cdot 9 \pm 4 \cdot 1$ until 2 days before parturition.

\section{Discussion}

The present study, concerned with the electrical activity patterns of various parts of the genital tract of the ewe throughout the entire course of pregnancy, is apparently the first to represent continuous ( $24 \mathrm{~h} /$ day) recordings of electrical activity, carried out for more than 7 months. Absence of significant disturbances was due to the use of thin $(0.120 \mathrm{~mm}) \mathrm{Ni}-\mathrm{Cr}$ electrodes which minimized animal discomfort and allowed normal pregnancy and parturition in 4 out of the 6 ewes. Whether the electrodes were responsible for the failure of gestation in 2 ewes cannot be assessed, but the presence of electrodes on both curvatures of the uterine horns in these 2 ewes could have impaired normal development of pregnancy. 
Table 2. Timings and characteristics of electrical activity in the cervix of each of the 4 ewes from Day 5 (Day $0=$ mating) until 2 days before parturition

\begin{tabular}{|c|c|c|c|c|c|}
\hline & Ewe 1* & Ewe $2 \dagger$ & Ewe $3^{*}$ & Ewe $4 \dagger$ & Mean \pm s.d. \\
\hline \multicolumn{6}{|l|}{ Day of pregnancy } \\
\hline Onset of 2 nd phase & 37 & 34 & 26 & 37 & $33 \cdot 5+5 \cdot 2$ \\
\hline Maximal activity & 45 & 51 & 39 & 57 & $48 \cdot 0 \pm 7 \cdot 8$ \\
\hline End of 2nd phase & 57 & 83 & 58 & 77 & $68 \cdot 8 \pm 13 \cdot 2$ \\
\hline \multicolumn{6}{|l|}{ Duration (days) } \\
\hline Ist phase & 32 & 29 & 21 & 32 & $28 \cdot 5 \pm 5 \cdot 2$ \\
\hline 2nd phase & 21 & 50 & 33 & 41 & $36 \cdot 3 \pm 12 \cdot 3$ \\
\hline 3rd phase & 86 & 61 & 89 & 67 & $75.8 \pm 13.8$ \\
\hline \multicolumn{6}{|l|}{ No. of activity episodes/day } \\
\hline 1st phase $\S$ & $\begin{array}{l}10 \cdot 6 \pm 3 \cdot 0 \\
(n=32)\end{array}$ & $\begin{array}{l}10 \cdot 0 \pm 3 \cdot 1 \\
(n=29)\end{array}$ & $\begin{array}{c}7 \cdot 8 \pm 4 \cdot 9 \\
(n=21)\end{array}$ & $\begin{array}{l}10 \cdot 2 \pm 4 \cdot 1 \\
(n=32)\end{array}$ & $9 \cdot 7 \pm 1 \cdot 3$ \\
\hline 2nd phase $\ddagger$ & 51 & 63 & 64 & 100 & $69 \cdot 5 \pm 21 \cdot 2$ \\
\hline 3rd phase & $\begin{array}{c}18 \cdot 0 \pm 5 \cdot 4 \\
(n=86)\end{array}$ & $\begin{array}{c}20 \cdot 2 \pm 5 \cdot 8 \\
(n=61)\end{array}$ & $\begin{array}{l}18 \cdot 3 \pm 6 \cdot 6 \\
(n=89)\end{array}$ & $\begin{array}{c}26.9 \pm 7 \cdot 1 \\
(n=67)\end{array}$ & $20 \cdot 9 \pm 4 \cdot 1$ \\
\hline \multicolumn{6}{|l|}{ Total activity } \\
\hline Total no. of episodes & 2674 & 3329 & 3115 & 3940 & $3264 \cdot 5 \pm 526 \cdot 5$ \\
\hline Mean duration $(\mathrm{min}) \uparrow$ & $\begin{array}{c}6 \cdot 6 \pm 1 \cdot 8 \\
(n=222)\end{array}$ & $\begin{array}{c}5 \cdot 9 \pm 1 \cdot 0 \\
(n=274)\end{array}$ & $\begin{array}{c}7 \cdot 8 \pm 1 \cdot 4 \\
(n=290)\end{array}$ & $\begin{array}{c}7 \cdot 1 \pm 1 \cdot 2 \\
(n=269)\end{array}$ & $6.9 \pm 0.8$ \\
\hline Total duration (h) & $294 \cdot 1$ & $327 \cdot 4$ & $405 \cdot 0$ & $466 \cdot 2$ & $373 \cdot 2 \pm 77 \cdot 5$ \\
\hline Total time of pregnancy $(\mathrm{h}) \|$ & 3336 & 3360 & 3432 & 3360 & $3372 \cdot 0 \pm 41 \cdot 6$ \\
\hline$\%$ activity of total time & $8 \cdot 8 \%$ & $9.7 \%$ & $11 \cdot 8 \%$ & $13.9 \%$ & $11.0 \%$ \\
\hline
\end{tabular}

* Singleton pregnancy.

$\dagger$ Twin pregnancy.

$\ddagger$ Peak value.

$\S$ Mean \pm s.d. for the no. of days indicated $(n)$.

Tा Mean \pm s.d. duration of episodes $(n)$ of regular activity measured during samples of direct records taken randomly throughout pregnancy.

\| Calculated from Day 5 until 2 days before parturition in each ewe; these values are $<6 \%$ higher than the actual time of analysis.

The transient inhibition clearly observed in one ewe at the time of mating was compatible with the reported effects of stress (Bontekoë, Blacquière, Naaktgeboren, Dieleman \& Willems, 1977). Conversely, the absence of significant motility changes in 5 out of the 6 ewes disagrees with the findings of Lehrer, Schindler, Brown \& Fischler (1978/79) who noted a significant increase, after mating, in both amplitude and frequency of pressure cycles, as recorded by means of intraluminal pressure-sensitive telemetric transducers. Similarly, Lightfoot (1970) found a "highly characteristic contractile response in both the uterus and cervix" of oestrous ewes, which was not attributed to the release of endogenous oxytocin. During oestrus, reactivity of the uterus of the ewe to oxytocin is maximal (Roberts, McCracken, Gavagan \& Soloff, 1976), and even low doses of the hormone, released by the neurohypophysis after coitus, would be able to activate strongly the whole genital tract. In oestrus, the introduction of a speculum into the vagina, which is a stimulus known to provoke endogenous oxytocin release, significantly activated the motility of the genital tract of ewes (unpublished observation). This is in agreement with the findings of Prud'homme \& Rousseau (1982) on the uterus, but such an activation was not observed during or after mating in the present study. Absence of significant oxytocin release at the time of mating has been reported for cattle (Schams, Baumann \& Leidl, 1982) and ewes (Hawker, Roberts \& Walmsley, 1959).

The present study reveals striking similarities in the temporal development of activity patterns in the 4 ewes with normal pregnancies. The basic pattern was similar to that described for the last month of pregnancy (Toutain et al., 1983). On the basis of the daily number of the so-called regular activity episodes, three distinct phases could be recognized. This finding deserves attention with regard to the endocrinological aspects of the ovine pregnancy. 
During the first phase, between Days 5 and 41 after mating, the activity pattern of the genital tract was similar to that observed during the cyclic luteal phase, i.e. no activity at all in the great curvature of the uterus and the synchronous cyclic occurrence of regular activity of the cervix and the lesser curvature of the uterus. During this period the embryo successively undergoes a free living stage (until about Day 15) and a weak attachment to the endometrium (until about Day 4555): it can be easily flushed from the uterus (Moor \& Rowson, 1964) and the absence of uterine motility is probably the reason why attachment occurs almost always in the uterine horn ipsilateral to the corpus luteum (Reimers et al., 1973). The mechanism by which twins originating from the same ovary become attached in each horn remains to be explained. This situation contrasts sharply with that of polytocous animals such as sows, for which the spacing of embryos is at least partly explained in terms of uterine motility (Pope, Maurer \& Stormshak, 1982).

The second phase began about 42 days after mating and was characterized by the onset and the rapid increase of uterine activity. Within 7 days, the uterus reached its highest level of activity during pregnancy. The appearance of uterine activity at this time agrees with the results of Van der Weyden et al. (1981) of onset of uterine activity episodes at a frequency of $2.6 \pm 1.2$ per $2 \mathrm{~h}$ in several recordings made between 49 and 55 days of pregnancy. The increase in activity can be explained in terms of oestrogen production by the conceptus. According to Koligian \& Stormshak (1976) the degree of attachment between maternal and fetal cotyledons greatly increases in complexity between Days 45 and 55 . In addition, placental weight increases from $<100 \mathrm{~g}$ before Day 40 to almost $200 \mathrm{~g}$ by Day 55 (Bedford, Challis, Harrison \& Heap, 1972). Improvement of the passage of cholesterol from the maternal to the fetal circulation has been suggested to be due to the increase in the extent of interdigitations by microvilli (Koligian \& Stormshak, 1976). Therefore, it can be suggested that the conceptus produces enough oestrogens at this time to trigger uterine activity, which is oestrogen-dependent. Carnegie \& Robertson (1978) have shown that oestrone sulphate in sheep allantoic fluid becomes detectable by Day $31(123 \mathrm{pg} / \mathrm{ml})$ and increases rapidly to a peak by Day $46(14 \cdot 2 \mathrm{ng} / \mathrm{ml})$. The frequency of regular activity of the cervix, which is influenced by oestrogens (Garcia-Villar et al., 1982a), rose significantly from Day 33 to Day 48 after mating. Peak values were obtained for the cervix and pregnant uterus around Days 48-49. Thereafter, a progressive decrease was observed during the next 19-20 days. Carnegie \& Robertson (1978) reported a drop of oestrone sulphate concentrations in allantoic fluid from Day 46 to Days 55-65 after mating. In addition, the placental contribution to circulating progesterone concentrations has been shown to begin at Day 52 and to rise until Day 65 (Ricketts \& Flint, 1980). These data are compatible with the progressive slowing down of genital tract activity recorded before a steady state plateau was reached by Day 68 .

During the third phase, the frequency of regular activity episodes plateaued until 2 days before parturition. The absence of significant changes in the activity pattern has been already reported for the last month of pregnancy (Toutain et al., 1983). During this phase, parallel increases in peripheral plasma concentrations of oestrogen and progesterone have been reported (Bassett \& Thorburn, 1973; Carnegie \& Robertson, 1978). A similar change has been reported for myometrial tissue (Rawlings \& Ward, 1976). The parallel increase of the two steroid hormones perhaps explains the relative stability of genital tract activity observed until the peripartal period.

From the above, it can be suggested that the motility events of the pregnant genital tract are under the control of sex steroid hormones produced by the feto-placental unit. The main oestrogen, oestrone sulphate, diffuses through the membranes of the chorionic vesicle to the uterus where it is deconjugated and reduced to biologically active oestradiol (Rossier \& Pierrepoint, 1974). Such a local transfer may explain why the gravid uterine horn began to be active when attachment took place and why the non-gravid horn, when present, remained almost quiescent during the whole pregnancy, because very few placentomes are present in this location.

No direct contact exists between the cervix and the conceptus, but the development of cervical activity is very similar to that of the gravid uterus, except during the first phase. Indeed, both the cervix and small uterine curvature exhibit activity before the conceptus starts to secrete oestrogen, 
although this activity remains at a relatively low level. Thereafter, when the feto-placental unit secretes enough oestrogens, it is likely that increased cervical activity could be under the control of the conceptus via myogenic pathways in the small curvature.

We thank Mrs C. Soual, G. Costes and Mr M. Caussette, J. P. Soula and G. Galy for technical assistance and animal care.

\section{References}

Bassett, J.M. \& Thorburn, G.D. (1973) Circulating levels of progesterone and corticosteroids in the pregnant ewe and its foetus. In The Endocrinology of Pregnancy and Parturition. Experimental Studies in the Sheep, pp. 126-140. Ed. C. G. Pierrepoint. Alpha Omega Alpha, Cardiff.

Bedford, C.A., Challis, J.R.G., Harrison, F.A. \& Heap, R.B. (1972) The role of oestrogens and progesterone in the onset of parturition in various species. $J$. Reprod. Fert., Suppl. 16, 1-23.

Bontekoë, E.H.M., Blacquière, J.F., Naaktgeboren, C., Dieleman, S.J. \& Willems, P.P.M. (1977) Influence of environmental disturbances on uterine motility during pregnancy and parturition in rabbit and sheep. Behat. Processes 2, 41-73.

Carnegie, J.A. \& Robertson, H.A. (1978) Conjugated and unconjugated estrogens in fetal and maternal fluids of the pregnant ewe: a possible role for estrone sulfate during early pregnancy. Biol. Reprod. 19, 202211.

Garcia-Villar, R., Toutain, P.L., Moré, J. \& Ruckebusch, Y. (1982a) Spontaneous motility of the cervix in cyclic and ovariectomized ewes and changes induced by exogenous hormones. J. Reprod. Fert. 66, 317-326.

Garcia-Villar, R., Toutain, P.L. \& Ruckebusch, Y. (1982b) Electromyographic evaluation of the spontaneous and drug-induced motility of the cervix in sheep. J. Pharmacol. Meth. 7, 83-90.

Harding, R., Poore, E.R., Bailey, A., Thorburn, G.D., Jansen, C.A.M. \& Nathanielsz, P.W. (1982) Electromyographic activity of the non pregnant and pregnant sheep uterus. Am. J. Obstet. Gynec. 142, 448 457.

Hawker, R.W., Roberts, V.S. \& Walmsley, C.F. (1959) Oxytocin and oxytocic substance in blood extracts before and following copulation in sheep. Endocrinology 64, 309-310.

Hindson, J.C. \& Ward, W.R. (1973) Myometrial studies in the pregnant sheep. In The Endocrinology of Pregnancy and Parturition. Experimental Studies in Sheep, pp. 153-173. Ed. C. G. Pierrepoint. Alpha Omega Alpha, Cardiff.

Hindson, J.C., Schofield, B.M. \& Turner, C.B. (1968) Parturient pressures in the ovine uterus. J. Physiol., Lond. 195, 19-28.

Koligian, K.B. \& Stormshak, F. (1976) Progesterone synthesis by ovine fetal cotyledons in vitro. J. Anim. Sci. 42, 439-443.

Krishnamurti, C.R., Kitts, D.D., Kitts, W.D. \& Tompkins, J.G. (1982) Myoelectrical changes in the uterus of the sheep around parturition. J. Reprod. Fert. 64, 59-67.

Latour, A. (1973) Un dispositif simple d'analyse quantitative de l'électromyogramme intestinal chronique. Annls Rech. Vét. 4, 437-453.
Lehrer, A.R., Schindler, H., Brown, M.B. \& Fischler, H. (1978/79) The effect of mating, artificial insemination and fright on uterine motility of the oestrous ewe. Anim. Reprod. Sci. 1, 297-304.

Lightfoot, R.J. (1970) The contractile activity of the genital tract of the ewe in response to oxytocin and mating. J. Reprod. Fert. 21, 376, Abstr.

Moor, R.M. \& Rowson, L.E.A. (1964) Influence of the embryo and uterus on luteal function in the sheep. Nature, Lond. 201, 522-523.

Naaktgeboren, C., Pool, C., Van Der Weyden, G.C., Taverne, M.A.M., Schoof, A.G. \& Kroon, C.H. (1975) Elektrophysiologische Untersuchungen über die Uteruskontraktionen des Schafes wärend der Trächtigkeit und der Geburt. Z. Tierzuchtg. Züchtungsbiol. 92, 220-243.

Nathanielsz, P.W., Bailey, A., Poore, E.R., Thorburn, G.D. \& Harding, R. (1980) The relationship between myometrial activity and sleep state and breathing in fetal sheep throughout the last third of gestation. $A m$. J. Obstet. Gynec. 6, 653-659.

Pope, W.F., Maurer, R.R. \& Stormshak, F. (1982) Intrauterine migration of the porcine embryo, interaction of embryo uterine flushings and indomethacin on myometrial function in vitro. J. Anim. Sci. 55, 11691178.

Prud'homme, M.J. \& Bosc, M.J. (1977) Motricité utérine de la brebis, avant, pendant et après la parturition spontanée ou après traitement par la dexaméthasone. Annls Biol. anim. Biochim. Biophys. 17, 9-19.

Prud'homme, M.J. \& Rousseau, J.P. (1982) Etude des réponses motrices de l'utérus aux stimulations vaginales et utérines chez la brebis en oestrus. Reprod. Nutr. Develop. 22, 597-610.

Rawlings, N.C. \& Ward, W.R. (1976) Changes in steroid hormones in plasma and myometrium and uterine activity in ewes during late pregnancy and parturition. J. Reprod. Fert. 48, 355-360.

Reimers, T.J., Dziuk, P.J., Bahr, J., Sprecher, D.J., Webel, S.K. \& Harmon, B.G. (1973) Transuterine embryonal migration in sheep, anterioposterior orientation of pig and sheep fetuses and presentation of piglets at birth. J. Anim. Sci. 37, 12121217.

Ricketts, A.P. \& Flint, A.P.F. (1980) Onset of synthesis of progesterone by ovine placenta. J. Endocr. 86, 337347.

Roberts, J.S., McCracken, J.A., Gavagan, J.E. \& Solof, M.S. (1976) Oxytocin-stimulated release of prostaglandin $F_{2 a}$ from ovine endometrium in vitro: correlation with estrous cycle and oxytocin-receptor binding. Endocrinology 99, 1107-1114.

Rossier, G. \& Pierrepoint, C.G. (1974) Oestrogen metabolism in sheep myometrium. J. Reprod. Fert. 37, 43-49. 
Ruckebusch, Y. \& Buéno, L. (1976) An electromyographic study of uterotubal activity in the ewe. $J$. Reprod. Fert. 47, 221-227.

Schams, D., Baumann, G. \& Leidl, W. (1982) Oxytocin determination by radioimmunoassay in cattle. II. Effects of mating and stimulation of the genital tract in bulls, cow and heifers. Acta endocr., Copenh. 99, 218-223.
Toutain, P.L., Garcia-Villar, R., Hanzen, C. \& Ruckebusch, Y. (1983) Electrical and mechanical activity of the cervix in the ewe during pregnancy and parturition. J. Reprod. Fert. 68, 195-204.

Van der Weyden, G.C., Taverne, M.A.M., Dieleman, S.J. \& Fontijne, P. (1981) Myometrial electrical activity throughout the entire course of pregnancy in the ewe. Eur. J. Obstet. Gynaec. Reprod. Biol. 11, 347-354.

Received 20 January 1984 